\title{
EDITORIAL
}

\section{A new era in psychiatric training and assessment ${ }^{\dagger}$}

\author{
Dinesh Bhugra
}

Abstract The Royal College of Psychiatrists is well on the way to introducing its new curriculum and revised Membership (MRCPsych) examinations and assessments, in line with the requirements of the Postgraduate Medical Education and Training Board. The new structures might encourage trainees to ask themselves how and why they are studying and learning. Organisers of local MRCPsych courses will need to tailor their courses to fit these new structures, and this might be an optimum time for the College to consider whether it should take a more formal role in approving courses and judging trainees' participation in them.

Since 30 September 2005 the Postgraduate Medical Education and Training Board (PMETB) has been the responsible body for postgraduate training and assessments in the UK and for issuing Certificates of Completion of Training (CCTs), with the medical Royal Colleges working as its agents. One of the major tasks for PMETB has been to provide guidelines and principles for assessment of trainees. These basic principles are outlined by Vassilas and colleagues in their article in this issue of $A P T$ (Vassilas et al, 2007).

Membership of the Royal College of Psychiatrists (MRCPsych) is obtainable only through rigorous examinations but the characteristics of a good member go beyond the mere passing of these exams (Bhugra et al, 2007a). Similarly, it is crucial to acknowledge that local MRCPsych courses should do more than simply prepare trainees for the exams.

It is worth recalling that, in line with the Membership examinations of the other medical Royal Colleges, the MRCPsych examinations have been 'high-stakes' exams and, although over $90 \%$ of trainees manage to pass in four or so attempts, there has been an element of luck in some components, for example the long case. Whether the candidate gets a highly cooperative articulate patient with depression or a deeply suspicious paranoid patient

${ }^{+}$See pp. 239-250, this issue. with schizophrenia can influence the outcome. From next year the formal MRCPsych examinations will be an integral part of an overall assessment package. Three theory papers will assess candidates' knowledge, and a wide range of objective structured clinical examination (OSCE) stations, some complex and some specialty-specific, will assess their competence. Workplace-based assessments will complement the examination structure. Local MRCPsych courses will continue to play an important role in developing trainees' knowledge for the foreseeable future and trainees will have to attend them as part of overall eligibility. However, these changes mean that organisers of the courses will also have to change their approach.

\section{The purpose of learning}

As Vassilas and colleagues argue, there are different types of learning and trainees need to understand the motivations for learning. Strategic learning is motivated by a desire to be successful but may result in patchy learning of variable depth. Surface learning is motivated by fear of failure and a desire to complete a course. Herein lies the rub. Trainees using these methods tend to rely on learning by rote. In contrast, trainees who employ deep learning take an active rather than passive interest, as well as control in the subject matter and particularly in considering its practical relevance. They use this learning to 
help them carry out the important tasks related to their clinical work. A concern about any revision course is that it encourages strategic or superficial learning of facts. There is little doubt that sometimes new learning is undertaken to meet examination requirements rather than education for its own sake. Nevertheless there is widespread agreement that all doctors should have a sound knowledge base and therefore knowledge-based assessments are an integral part of the assessment process. Our patients and their carers expect nothing less.

Under the new curriculum and assessment matrix all assessments match the aims and objectives of the curriculum, so that studying for the examinations perhaps becomes secondary to learning to be a good doctor. This approach is implicit in the new competency-based curriculum and emphasis on workplace-based learning and workplace-based assessments (Bhugra et al, 2007b). The Royal College of Psychiatrists was the first medical Royal College to present its assessment matrix to PMETB, in April 2007, and to gain provisional approval.

\section{Present in body - but in mind?}

Two further factors deserve attention and debate. To date, the emphasis for trainees has been on course attendance rather than active participation. The eligibility criteria for application to take the MRCPsych examination include attendance at an MRCPsych course. Theoretically, physical attendance has been seen as sufficient. Whether the trainee has gained any knowledge has not been very clear, although it could be argued that passing the examination serves as a confirmation. There has always been an understanding that the trainee will attend at least $80 \%$ of the course sessions. Should there be any other way of judging participation in the course? Should the trainee be assessed on more than mere physical presence? How will e-learning and web-based learning change things?

\section{Will courses be fit for purpose?}

The second factor that the College needs to think about is the quality of courses. There have been informal discussions within the College to explore the possibility that it should take a formal role in approving courses. Among other things course content and pass rates would have to be considered. The quality of content is currently determined by the enthusiasm of local teachers and by the involvement of their university departments, although the latter may be more wrapped up in their own activities such as research. Local MRCPsych courses will survive provided they alter their teaching and style to match the new curriculum requirements. They will have to address trainees' competencies and how to develop their attitudes, knowledge and skills.

In due course the emphasis of MRCPsych courses will have to change to ensure delivery of the different components of the curriculum. They may well have to focus on the different types of workplacebased assessment. Ideally, courses should involve trainees in their design and delivery, and have proper input from patients and carers. The purpose of the MRCPsych course needs to be revisited and course organisers need to consider how best to include a structured introduction to the subject and help trainees with their continuing development throughout the speciality training years.

\section{Declaration of interest}

D. B. is Dean of the Royal College of Psychiatrists.

\section{References}

Bhugra, D., Sivakumar, K. \& Holsgrove, G. (2007a) Characteristics of a good psychiatrist. World Psychiatry, in press.

Bhugra, D., Malik, A. \& Brown, N. (eds) (2007b) Workplace-Based Assessments in Psychiatry. RCPsych Publications.

Vassilas, C. A., Kuruvilla, T., Gupta, V. et al (2007) Preparing trainees for the MRCPsych examinations. Advances in Psychiatric Treatment, 13, 239-250. 